\title{
Struggles of Norm Construction in the Global Nuclear Order: An Indian Perspective on the Formative Years
}

\author{
A Vinod Kumar*
}

\begin{abstract}
The existence of a global nuclear order as a conglomeration of norms, regimes, and institutions seems to have brought equilibrium to the governance of the Atom. Yet, the 'order' is dominated by the nonproliferation norm, which has curbed the spread of nuclear weapons though not their existence. The NPT, as the cornerstone treaty, to facilitate this process has faltered due to its incoherent conceptual framing and conflicting interpretations of its process and purpose. The goal of total elimination, however, has remained elusive. This article revisits the early struggles of nuclear norm construction through the perspective of an actor with multiple role identities such as a norm entrepreneur, crusader, and challenger.
\end{abstract}

Keywords: Nuclear Order, Regime, Stability, Norm Construction

\section{Introduction}

What was the purpose to be served by the existence of a global nuclear order? The general perceptions are that it should

\footnotetext{
* Associate Fellow with Institute for Defence Studies and Analysis, New Delhi, India; avinodkumar@outlook.com
} 
encompass a global architecture of regimes and institutions that could bring equilibrium, balance and sanity to the manner in which the affairs of the Atom are managed or governed. At a more specific level, one could conceive of rules, norms, instruments and structures that could work for a particular set of objectives, which, in this case, could be among the following: (a) inhibit the further spread of nuclear weapons and establish control over the technology to prevent its diffusion, (b) expand the civilian and peaceful potential of the Atom, and (c) move towards a world without nuclear weapons.

Irrespective of the nature of its evolution - be it power-centric, norm-oriented or security-driven, the global nuclear order symbolised the pursuit of these goals, singularly or in combination, though none of them was effectively fructified. Notwithstanding its early nascent formation through efforts to consolidate nuclear deterrence equations between the superpowers, an actual semblance of 'order' came about when multilateral consensus evolved to institutionalise the management of multiple applications of the Atom. Though an altruistic vision of promoting civilian nuclear energy was expounded as a rationale for the early initiatives, the key stimulant seemed to be the advent and threat of more states accessing the nuclear weapons technology. The fundamental impulse behind Eisenhower's Atom-for-Peace (1953), and the earlier attempt of the Baruch Plan (1946) could have been the aim or interest of the then nuclear powers to monopolise this technology and restrict its access. They executed the same through their bargain of promoting peaceful uses of nuclear energy to those nations that were willing to forego the right to develop nuclear weapons.

The establishment of the International Atomic Energy Agency (IAEA) was the first step towards an institutional mechanism to implement this bargain, but also laid the foundations of a regime, whose identity and objectives, however, was mired in conceptual confusion. In the intervening years between the 1950s and 1960s, the narratives on nuclear annihilation and halting the spread of nuclear weapons had germinated various approaches, including non-dissemination and non-acquisition, on the one hand (as a means to control or inhibit access to this technology), and 
disarmament, total elimination and abolition on the other (as path towards a world without nuclear weapons). The struggle between these approaches defined the shaping of the nuclear order, and the regime, in the formative years.

A reflection of this phenomenon is the composition of various platforms that came up under the auspices of the United Nations, including the Disarmament Commission (UNDC) and the Eighteen-Nation Disarmament Committee (ENDC) with the agenda of building global consensus on 'agreeable' end objectives and their contributing structures. ${ }^{1}$

Though disarmament was a recurring theme that influenced the early agenda of these forums, the intensifying Cold War rivalries between the two blocs made it difficult to find a common ground on the means towards this end. An example of this trend was the McCloy-Zorin talks which produced a US-Soviet Joint Statement on Agreed Principles for Disarmament Negotiations (1961) but failed to gather traction as the superpowers could not agree on a common draft for a disarmament treaty. ${ }^{2}$ On the other hand, the increase in a number of states attaining the capability to develop nuclear weapons, and the challenges of opening access to nuclear energy resources for all nations prompted the need for effective control and oversight over nuclear resources.

These impulses drove a marginal level of bloc cooperation to devise structures against wider dissemination of nuclear weapons technology although competing alliance politics delayed consensus on several of these proposed measures. Ireland's draft resolutions (1959-61) calling for steps to stop the transfer of nuclear weapons or technology and undertaking by non-weapon states not to manufacture nuclear weapons were among the early initiatives in this direction. ${ }^{3}$ However, much of the deliberations till 1965, when debate began on a non-proliferation treaty, continued to be on the phases of a potential disarmament treaty, timelines for reductions and progressing to a comprehensive test ban treaty, among others, which highlighted the divergences on the feasible route to disarmament though also opening the prospects for a global framework to stop the spread of nuclear weapons. ${ }^{4}$ 
The turnaround towards a 'non-proliferation' treaty was propelled by many factors:

(a) Despite the impetus for arms reductions, events like the Cuban Missile Crisis diminished possibilities of détente and fuelled the disinclination of superpowers' to curtail arsenals or restrict their augmentation.

(b) The Chinese nuclear test of October 1964 aggravated the security environment for many non-weapon states, mainly India, who demanded a comprehensive treaty that included not just disarmament and non-dissemination measures but also the elimination of existing arsenals and security guarantees against the threat or use of nuclear weapons by nuclear-armed states.

(c) The expansion of nuclear energy carried the inherent risk of misuse and diversion, which need an effective instrument that could inhibit the ability of states to proliferate. Further, the bargain of accessing nuclear energy resources in return for abstaining from the pursuit of nuclear weapons - needed to be formalised through a legal framework, which could ideally include total elimination as a long-term end objective.

\section{NPT: A Circumstantial Treaty}

The treaty on the non-proliferation of nuclear weapons (NPT), which was adopted by the UNGA through Resolution 2373 (XXII) on 12 June 1968, is treated as the cornerstone of the nonproliferation regime and has defined and shaped the nuclear order since its creation. Over the years, the treaty has evolved into a nearuniversal framework of non-proliferation with only four hold-outs, and the remaining, including those that voted against or abstained on Resolution 2373, subsequently joining the treaty. The treaty has accomplished the task of enforcing a global norm against the spread of nuclear weapons, though not a norm against nuclear weapons as such or facilitating measures towards eventual elimination. The NPT, though, was by no means an ideal instrument, and in turn, had emerged out of a flawed norm construction process - the impetus to find the means to eliminate nuclear weapons ended up formalising its possession in the hands of a few while prohibiting its pursuit by the rest. 
The treaty propounded a grand bargain: halt the spread of nuclear weapons with the non-nuclear weapon states (NNWS) not acquiring or manufacturing them, while the recognised nuclear weapon states (NWS) take measures to progress towards disarmament even as all countries benefit from uninterrupted access to peaceful uses of nuclear energy. The treaty is, thus, supposed to be resting on three pillars: non-proliferation, disarmament and peaceful uses of nuclear energy. Yet, can the three pillars co-exist in complementary roles when one of them prevails as the operational framework, another as an envisioned end-goal and the third remaining as a corollary? Put differently, can they have an egalitarian existence with one pillar (nonproliferation) dominating over the other two, by exercising control over another (peaceful uses of nuclear energy) even while its functional motto is to facilitate progress towards the third (disarmament). This imbalance strikes at the core of the three-pillar theory, and in turn illustrates why the treaty has ended up as an instrument to establish the non-proliferation norm, control access to nuclear energy resources, and only conceives of preferable conditions to move towards disarmament.

This complexity embodies not just a flawed process but also the structural deficiencies that shaped the nuclear order in the 1960s: (a) the superpowers held nuclear weapons as a currency of power and hegemony which drove their aversion to any disarmament instrument or provisions that could impinge their arsenals; (b) despite active participation in the ENDC debate by many members of both blocs, and supporting arguments of the non-aligned group, their eventual choice was to bandwagon with their bloc leaders; (c) non-proliferation emerged as a circumstantial formula, not an inevitable outcome of ENDC negotiations, as the superpowers had to manoeuvre a treaty draft that adopted some demands of the NNWS but none that affected their strategic calculations; (d) the 'hurried' adoption of 'non-proliferation' as the guiding theme or philosophy of the NPT, in their effort to stymie the disarmament provisions, led to its incoherent conceptual framing. The resultant incongruities, which were causal for many systemic problems that confronted the treaty and translated into crises for the regime and the order, could be encapsulated on the following lines. 


\section{Non-Proliferation - As a Means or an End?}

Can the twin goals of disarmament and non-proliferation go together? Rather, was non-proliferation the way the NPT conceived it actually designed to lead towards disarmament? It has become customary for observers of the non-proliferation system to cite unfavourable conditions in the global security environment as having stymied the progress towards disarmament or effective pursuit of Article VI. Yet, the NWS rarely seemed inclined to discard their nuclear arsenals completely, owing to their security dilemmas or competition and also because their great power status hinges on its possession. More significant, though, is the inchoate manner in which non-proliferation was conceptualised. Nonproliferation was an idea that caught the imagination of both sections - the NWS saw it as an opportunity to inhibit the emergence of newer weapon powers while the NNWS felt the concept covered all aspects of proliferation including vertical and horizontal proliferation. An agreement on non-proliferation was thus expected to be a durable means towards disarmament. However, the manner in which the treaty was drafted without defining its fundamental concepts and the imbalance inbuilt into its framework are a testament to the fact that the NPT was more of a political instrument - a result of rare superpower bonhomie driven by their common interests - and by no means a creative norm building exercise.

In the political din of negotiations, no attempt was made to define non-proliferation or its end objectives, nor enshrining how a sustained effort at non-proliferation is actually going to lead to disarmament. In other words, the treaty does not enunciate whether non-proliferation is a means towards disarmament or an end in itself. As a result, two conflicting approaches have been expounded by different sections: (a) non-proliferation was to establish a global framework to inhibit the further spread of nuclear weapons and technology alongside a series of incremental measures, pursued in a parallel and phased manner, and leading to a disarmament process through a treaty on general and complete disarmament; and (b) non-proliferation could facilitate the progress towards a tipping point - a post-proliferation world - from where proliferation no longer happens and sets the conditions for a 40 
disarmament instrument to be initiated. Both these approaches have not achieved traction beyond a point of stasis with their paths often overlapping, leading to a stalemate and recurring crisis.

Non-proliferation as a concept throws up multiple dimensions. When taken per se as a nomenclature, non-proliferation could innately connote an end - as a mitigation point of proliferation or no more proliferation. However, its perceived conception is of a means as enduring measures to ensure that states do not proliferate and enable progress towards disarmament and total elimination. The uninhibited pursuit of nuclear weapons in the 1950s and early 1960s and resultant clamour for disarmament had influenced the NPT negotiations to the extent that the superpowers had to project non-proliferation as a means to an end -the promise of a world with no more proliferation or when states no longer pursue nuclear weapons. On an ideal course, this concept should have been a process which starts as a means and culminates as an end. In its expandable manifestations, the treaty has institutionalised nonproliferation as the means to pursue three ends: (1) mitigate possibilities of nuclear weapons proliferation, (2) optimal usage of nuclear energy without risk of proliferation, and (3) facilitate a post-proliferation world that will create conditions for disarmament and total elimination. However, this postulation could be challenged as the goal of a post-proliferation world is not sanctified in the NPT, and in reality seems to be tall order for two reasons: (a) disarmament could be delayed until this condition is achieved, and (b) such a scenario may be forever elusive.

The NPT preamble does not suggest the possibility of a postproliferation world. It though describes an ideal scenario which could be akin to such a condition - an earliest possible date when nuclear arms race ceases to exist, all test explosions are discontinued, international tension eases and trust is strengthened. Such a scenario, the preamble conceives, could facilitate the cessation of the manufacture of nuclear weapons, liquidation of all stockpiles and elimination of national arsenals, though only pursuant to a treaty on general and complete disarmament. Though many of these conditions are unlikely to be met in the foreseeable future, over the years, votaries of disarmament have assumed that a treaty for this purpose could be negotiated concurrently and 
preferably by the 25-year timeline when the treaty was to be reviewed for extension. It is noteworthy that Article X (2) does not entail the termination of the treaty at this point, thus connoting that the search for a post-proliferation world or a stand-alone disarmament instrument could be infinite.

\section{The End-Objectives}

What then is the end objective of the treaty, and what it implies for the nuclear order? The NPT does not solemnise a single-point objective - of a world without nuclear weapons. Instead, its preamble conceives the formulation of an agreement on the prevention of wider dissemination of nuclear weapons, which will be complemented by measures to promote nuclear energy within the framework of IAEA safeguards. The prudent management of nuclear resources through these measures should enable stateparties to cooperate for effective measures in the direction of nuclear arms disarmament, along with the cessation of the arms race. The progress towards this stage should lead to a treaty on general and complete disarmament (NPT).

When read together, it may seem that the treaty demands a set of actions that will naturally culminate in a disarmament treaty. In practice, though, the preamble defines the treaty as a conglomeration of measures to stop the spread of nuclear weapons and, by consequence, create ideal conditions for disarmament. Whether disarmament will ultimately remove nuclear weapons will be a matter of practical realisation, of how the technology or know-how is going to be controlled thereafter. Nonetheless, the absence of an enshrined objective of total elimination and a designated timeframe to achieve it leaves the NPT open-ended and destined for eternity.

What the NPT text omits, though, is emphatically included in the 1995 Extension Conference resolution. Decision 3 states that: "Having reviewed the operation of the Treaty...its extension and universal adherence are essential to... the attainment of the ultimate goals of the complete elimination of nuclear weapons and a treaty on general and complete disarmament...". By affirming that the ultimate goal is a disarmament treaty and total elimination, Decision 3 
implies the timeline to fulfill this goal may be indeterminable. The global nuclear order may, in the meantime, remain as an enduring system to pursue this goal. Its actual utility, though, will be in managing residual applications of the Atom, which will be a functionality that may surpass the goal of total elimination. For, the normative management of nuclear energy will require a dependable set of global governance systems for the infinite future.

\section{The Power-Hegemonic Influence}

The ENDC produced not just a cornerstone treaty to anchor the non-proliferation regime, but also reinforced the hegemonic influence over the international system and the power-centric impulses of the nuclear order. Since the espousal of the atoms-forpeace plan, the world has been divided into nuclear 'haves' and 'have-nots', with the NPT formalising this condition. That the final NPT text was a US-Soviet joint draft is only a further illustration of the fact that the superpowers framed the rules of the game. Their joint-draft did not address the key demand of the NNWS for a balanced and non-discriminatory treaty nor were they willing to be subjected to any proposals that affected their arsenals or strategic supremacy. Two notable examples are: (a) the treaty completely disavowing the principles of UNGA Resolution 2028 of 19 November 1965, based on a joint memorandum of eight nonaligned nations, and (b) rejection of the Fanfani proposal for a partial non-proliferation treaty - wherein nuclear powers cease production of nuclear weapons and begin reductions in the first stage, followed by a comprehensive treaty with undertaking by NNWS not to acquire or manufacture them. ${ }^{5}$

Despite a major section of the NNWS terming the US-Soviet draft as promoting a fragile non-proliferation instrument, the superpowers were clear that the aim of the treaty should be to check the further spread of nuclear weapons and hence tying up non-proliferation to other measures could cause an impasse. Eventually, the allurement of accessing nuclear energy resources and the threat of a deadlock was effectively exploited to get 95 states to vote in favour of the treaty, while only 4 voted against with the remaining 20 abstaining. Despite the wide endorsement of the treaty's flaws, the dominant sentiment was that having a treaty 
was better than having none and that no agreement on disarmament was possible without an agreement to prevent further spread of nuclear weapons. In fact, state-parties had different perceptions of the utility of the treaty: only a few NNWS had perceived it as a genuine means towards complete disarmament while a large section had assumed it as a guarantee against potential acquisition of nuclear weapons by their rivals or neighbours, even as most saw it as a durable framework to enable access to peaceful uses of nuclear energy (Horovitz, 2015).

Despite its flawed construction, the treaty gave a philosophical and normative construct to the global nuclear order and completed the first phase of its evolution from the post-war years to a period of détente. The superpower bonhomie that facilitated the treaty's creation anchored an arms control culture that fuelled major initiatives for reductions and nuclear restraint. More importantly, the NPT exemplified how power and interests decisively shaped the mechanisms of the international system, irrespective of the collective security principles that drove their creation or the normative values behind their conception. The instruments of the regime have since been largely controlled by the hegemon (US) and a group of guardians (mostly of the liberal security community), who have determined the nature and shape of the collective security institutions that emerge from time to time. ${ }^{6}$ Almost all normative structures and paradigmatic shifts invariably suit the interests of this group, whose leverage is determined by their power and/or economic and technological capabilities.

Even when viewed from a constructivist 'learning' and 'schooling' paradigm, it is clear that the hegemon and the guardians have predominantly determined the norms of international nuclear behaviour, with the rest having to adjust their policies to their benchmarks. The NPT, though, could be an insightful case in explaining the process of norm-construction: how a disparate group of norm-entrepreneurs constructed a norm against spread of nuclear weapons, and cascaded it through a treaty, which was subsequently internalised by the vast section of state-parties who acceded in the years to come, through socialisation and incentives (Finnemore, 1998). The intense polemics at the NPT negotiations, followed by the decisive swing in favour of the resolution are all 
apt examples of the learning and socialisation process that were initiated for this normative cycle. Similarly, this process also witnessed remarkable levels of norm contestation and advent of a new genre of actors beyond the scope of entrepreneurship, who consistently resisted the new norm, sought innovations or norm change during its construction phases. The Indian record is peculiar in this respect - first in crusading for the elimination of nuclear weapons and the activism it undertook in shaping various functional and normative structures, and eventually going on to resisting them for their 'discriminatory' character and effeteness in fulfilling the perceived goals.

\section{India and the NPT: From Crusader to Challenger}

India's participation in the formative years of the nuclear order and its contribution to the normative process traversed multiple role identities - of a crusader, a norm entrepreneur and eventually as a challenger and outlier - covering decadal phases of India's nuclear diplomacy from 1954 to 1974 . The first phase in the 1950s was an era of Nehruvian internationalism and idealism - marked by activism on nuclear disarmament and advocating the cause of the third world in the evolving nuclear order. Jawaharlal Nehru's proposal of 1954 for a 'standstill agreement' to halt atmospheric testing also included the earliest calls for ceasing nuclear weapons production and for total elimination. ${ }^{7}$ India was an active contributor to the atoms-for-peace debate and establishment of the IAEA, especially in representing the interests of the have-nots in its board of governors and raising concerns on the intrusive nature of safeguards. It was, however, the ideational vision of a grand disarmament instrument that shaped India's initial positions when various proposals were being debated, in search of an elusive treaty.

The second phase began with the Chinese nuclear test of October 1964, which led to the emergence of a pro-bomb lobby in the country. The country's leadership was faced with the predicament of having to decide between the Nehruvian ideals and realistic options to secure its national interest. India's role as a normentrepreneur took shape during this phase when, along with other non-aligned members, it sought to influence the ENDC agenda by 
placing security guarantees for non-weapon states along with tangible progress towards disarmament as the key attributes of a potential treaty. The Indian representative introduced 'proliferation' in the lexicon of the debate (before the treaty took the non-proliferation turn) besides authoring joint memorandum with eight NAM countries to facilitate Resolution $2028 .{ }^{8}$

The third phase was of resistance, which began in 1967 when the US-Soviet joint draft was shaping up. India (and Brazil) was at the forefront to resist the draft for being imbalanced and discriminatory, and for heaping prohibitions on the NNWS while the nuclear powers sought to legitimise their arsenals. The absence of security guarantees in the treaty text and the restrictions on PNEs were among the core issues that fed India's resistance. With the increasing number of Chinese nuclear tests and pressure intensifying for a domestic weapon programme, the leadership had few options but to reject the final draft and promise 'measures to safeguard India's security'. Around the time the NPT opened for signature, India decided on an active nuclearisation mission, based on the Vikram Sarabhai plan, which entailed the building of a proactive nuclear infrastructure (complemented by space and electronics sectors) to anchor a self-reliant nuclear energy programme, while also providing the wherewithal for a weaponisation mission, if and when the need arises. ${ }^{9}$ Eventually, India undertook a PNE in May 1974 and had remained as an outlier in the years to come.

The decision to reject the NPT and conduct the PNE denotes not just raising a challenge to the way in which the nuclear order was being shaped by the superpowers. Despite placing disarmament as its core ideational objective, India was concerned about the implications of nuclear weapons being introduced in its neighbourhood, and could not accept a treaty limiting its options to deal with this challenge. India's NPT decision seems to be an outcome of this peculiar dichotomy - of wanting a disarmament end-goal but not at the expense of its security. An underlying conflict was seemingly at work with the leadership caught between its ideological commitments and the pressure of policy realism to keep all its options open. Between June 1965 and January 1967, India had lost the window of undertaking a nuclear test and 
qualifying as a nuclear weapon state, due to the ill-informed judgment of how the strategic environment was evolving or how the treaty was shaping up, while also being handicapped by its principled position against nuclear weapons. The subsequent course to an independent standing was influenced by three intricate issues:

(a) Orthodoxy on disarmament: In the final days of negotiations, New Delhi had stated that India will only accept a treaty that included credible disarmament obligations. The leadership had hoped that the treaty would emerge as a strong instrument of disarmament and would enable it to maintain its ideational status, without having to change the peaceful nature of its nuclear programme. There were a handful of reasons for India's lack of confidence on the NPT as a vehicle for disarmament. First, China was neither a party to the NPT negotiations nor committed to acceding to the treaty. Any disarmament process, hence, would not cover the fledging Chinese arsenal as long as Beijing stayed away. Second, the ability of the NPT to facilitate disarmament was in question as there were no provisions for the liquidation of stockpiles or for incremental steps like a test ban and a production freeze for fissile materials. India rejected the preamble as mere pious declarations and doubted the legal validity of Article VI to pursue disarmament in good faith. Third, India felt that arsenals are only likely to grow rather than being eliminated with the intensifying arms race, which may give little scope for good-faith negotiations to realistically happen.

(b) Security guarantees: India rejected UNSCR 255 of 19 June 1968 (providing assurance to NNWS against the threat of nuclear aggression) with a pontifical assertion that 'real security comes through disarmament'. This position was the outcome of India's complicated approach: on the one hand, it wanted the nuclear powers to institutionalise guarantees through the NPT, and on the other, it negotiated with the superpowers in an attempt to seek assurances on the Chinese threat. A series of interactions -from Prime Minister Lal Bahadur Shastri's meeting with British premier Harold Wilson and L.K. Jha's mission to Moscow and Washington were undertaken to explore a broad security guarantee framework. ${ }^{10}$ While the Shastri mission ended up in confusion as 
his own ministers questioned the validity of seeking a 'nuclear umbrella' from superpowers and its implications for India's nonalignment policy. On the other hand, Moscow proposed a guarantee through the UNSC route if India signed the NPT - a formula that the Johnson administration also endorsed.11 Eventually, India rejected the UNSC route and insisted on guarantees being enshrined in the NPT text. As a matter of fact, the leadership doubted if strategic interests would allow the nuclear powers to fulfill these guarantees, whether there would be immediate reprisal from the nuclear powers in the event of a nuclear attack, and whether such guarantees would 'deter' China.

(c) Peaceful nuclear explosions: India had profoundly resisted the US proposal of offering PNE technology on 'commercial' basis by terming it as an "atomic commercial super-monopoly" and "atomic apartheid" (ENDC). India's approach to PNEs though has been inconsistent. On the one hand, India made a strong distinction between PNEs as peaceful applications and all other forms of nuclear testing, which it sought to be banned. On the other, India made only broad references to its application for developmental projects. In the meantime, Shastri was known to have sanctioned the Subterranean Nuclear Explosion Program (SNEP), on the lines of the US Plowshares. There are records of US officials recommending the sharing of this technology with India. The Indian government, though, was non-committal until 1972 on PNE experimentations pursued by the Department of Atomic Energy (DAE). It was not until 1974 that various articulations on its applications were being formally made. ${ }^{12}$ Though the actual reasons are still unclear on why the PNE was undertaken four years after the NPT entered into force, Raja Ramana talks of Indira Gandhi decreeing that "the experiment should be carried out for the simple reason that India required such a demonstration" (Ramanna, 1991). It may seem that the PNE was not just a demonstration of capability (with a weapon dimension), but also an effort to signal its determination to pursue a nuclear future on its own terms, by departing from the normative framework established by the NPT and the nuclear order. 


\section{Conclusion}

The formation of the nuclear order and its key structures shows the levels to which great powers can cooperate in a system of anarchy and self-help to construct collective security instruments that cater to their common interests. The relative success in maintaining 'order' in the nuclear realm and governing varied applications of the Atom could be attributed to this camaraderie. Despite the inherent imbalances and engrafted discrimination, the guardians of the order had largely managed to mitigate the ' $n$ th' nuclear-armed nation, restrict proliferation risks to the minimum and maintain a universal framework of oversight and accountability. Yet, much of these accomplishments seemed to be guided by the convergence of national interests and the urge to maintain status quo of preserving the closed nuclear club, controlling access to nuclear commerce based on their own guidelines and economic-technological gains, and maintain a deterrence-based security architecture that retains the primacy of nuclear weapons.

The endurance of the nuclear order is dependent on the nonproliferation regime, which has faltered on the weaknesses of the cornerstone treaty. Though many challenges have been addressed through new instruments and paradigmatic shifts, the NPT has slid into a perennial crisis owing to the conflict between its pillars and competing objectives. In recent years, many voices are demanding progress towards the original goal of total elimination, through stand-alone instruments. A new paradigm is being offered by highlighting the 'humanitarian consequences' of nuclear weapons. That these initiatives have not gained much traction could be proof of how power dynamics continue to drive the system, as also the divergent perceptions on the raison d'être of the nuclear order.

The Indian case underscores the inevitability of normative contestation and how states could resist a norm construction cycle if it disagrees with its inherent biases or seek normative innovations to change the status quo. The Indian resistance also highlights the fact that norm construction need not be perceived as an altruistic endeavour, which could naturally attract adherence, and hence will be subjected to the dynamics of power balancing and dissent. The efforts to internalize a new norm, hence, entail a 
strenuous path of socialisation which involves learning and incentives, as also coercion. That many states took years to accede to the treaty is a testament to the kind of internalisation struggles that define this landscape. Also, the prevalence of nuclear-capable hold-outs, howsoever small in number, and their ability to challenge the normative order through acts of deviance is a testament to the challenges that even a power-centric order could occasionally be subjected to. The urge to develop an alternative norm-oriented order could decisively disturb the status quo.

\section{References}

Finnemore, M., \& Kathryn, S. (1998). International norm dynamics and political change. International Organization, 52(4), 887-917

Horovitz, L. (2015). Beyond pessimism: why the treaty on the nonproliferation of nuclear weapons will not collapse. The Journal of Strategic Studies, 38(2), 126-158

NPT. (2005). NPT preamble. Retrieved from http:// www.un.org/ en/conf/ npt/ 2005/ npttreaty.html

Ramanna, R. (1991). Years of Pilgrimage. New Delhi: Viking

\section{End Notes}

1 The UNDC was established by General Assembly Resolution 502 (VI) on 11 January 1952 to devise disarmament measures. Through Resolution 1252 D (XIII) of 4 November 1958, the Commission was reconstituted to comprise all UN members, and last met in 1960. The ENDC was announced on 13 December 1961, and endorsed by Resolution 1722 (XVI) of 20 December 1961. Members included Brazil, Bulgaria, Burma, Canada, Czechoslovakia, Ethiopia, France, India, Italy, Mexico, Nigeria, Poland, Romania, Sweden, UAR., UK, with US and USSR as its Permanent Co-chairmen.

2 The US and Soviet delegations initiated the Zorin-McCloy talks that led to a Joint Statement of Agreed Principles for Disarmament Negotiations in September 1961. See text of Joint Statement on Agreed Principles at: https://disarmament-library.un.org/UNODA/ Library.nsf/1cf71faffad96cd38525796500789846/d0276def8b6fad0f8525 7a130054e158/\$FILE/A-4879.pdf, accessed in June 2015.

3 Ireland submitted drafts on 'non-dissemination' and for measures against 'relinquishing control or transferring information on nuclear 
weapons manufacturing' in 1959 and 1960, but were opposed on each occasion by one of the superpowers.

4 While the Soviets suggested a four-year period of reductions and disarmament, the US talked of a phased programme wherein the first stage of a three-year period will be used to freeze production of nuclear weapons, the second stage to make major inroads into stockpiles and the third for total elimination.

5The five principles included: (a) the treaty should be void of any loopholes which might permit states to proliferate; (b) it should embody acceptable balance of mutual responsibilities and obligations; (c) the treaty should be a step towards general and complete disarmament, particularly nuclear disarmament; $(d)$ there should be acceptable and workable provisions to ensure its effectiveness; and (e) it should not adversely affect the right to conclude regional treaties to ensure total absence of nuclear weapons in respective territories.The joint memorandum on non-proliferation (ENDC/158) was submitted to the 233rd meeting of UNGA by Brazil, Burma, Ethiopia, India, Mexico, Nigeria, Sweden and the United Arab Republic.

6 The Liberal Security Community (LSC), according to Glenn Chafetz, is a group of liberal democracies with common security interests, and shared political and economic values, who control the affairs of the nuclear order, for detail see Glenn Chafetz, "The Political Psychology of the Nuclear Non-proliferation Regime," The Journal of Politics, 57(3), August 1995.

7 Jawaharlal Nehru made this proposal in the Lok Sabha on 10 May 1954, which was forwarded to the UN Secretary General in a letter (DC/44 and Corr.1).

${ }^{8}$ V.C. Trivedi at ENDC meeting P.V.174, 12 March 1964. Also, in a letter to the UN Secretary General dated 10 October 1964, Indian envoy, B.N. Chakravarthi, requested that an item entitled 'Non-proliferation of nuclear weapons' be inscribed in the agenda for the Nineteenth session of the UNGA.

9 Sarabhai plan reproduced in Special Issue of IDSA Journal, Vol. 3 (1) July 1970.

${ }^{10}$ Memorandum of Conversation, President Johnson with L.K. Jha, B.K. Nehru, V. Sarabhai and W.W. Rostow, Washington, 19 April 1967, Foreign Relations of the United States (XXV), South Asia, Document 440. Also see telegram from Special Assistant to President Johnson, Document 438, and Notes by L.K. Jha to the Prime Minister's 
Secretariat, P.N. Haksar Papers, IIIrdInstallment, Subject File No. 111, Nehru Memorial Museum and Library, New Delhi.

${ }^{11}$ Memorandum of Conversation, Secretary Dean Rusk and Foreign Minister Gromyko, 23 June 1967, Foreign Relations of the United States 1964-68 (XI), Arms Control and Disarmament, Document 198.

12 In a Working Paper presented at the Divonne meeting organised by the Arms Control Association and Carnegie Endowment for International Peace, 9-11 September, 1974, V.C. Trivedi talks about the broad PNE applications that India envisages. 